\title{
ALLOWING SERVICE USERS TO DIE AT HOME: PALLIATIVE CARE FOR VULNERABLY HOUSED AND HOMELESS INDIVIDUALS
}

\author{
by \\ An MRP \\ presented to Ryerson University \\ in partial fulfillment of the \\ requirements for the degree of \\ Master of Social Work \\ in the Program of \\ Social Work
}

Taggart Archer, BA, Trent University 2010, BSW, Waterloo University 2013

Toronto, Ontario, Canada, 2017

(C) Taggart Archer 2017 


\section{AUTHOR'S DECLARATION FOR ELECTRONIC SUBMISSION OF A MRP}

I hereby declare that I am the sole author of this MRP. This is a true copy of the MRP, including any required final revisions.

I authorize Ryerson University to lend this MRP to other institutions or individuals for the purpose of scholarly research

I further authorize Ryerson University to reproduce this MRP by photocopying or by other means, in total or in part, at the request of other institutions or individuals for the purpose of scholarly research.

I understand that my MRP may be made electronically available to the public. 


\begin{abstract}
Allowing Service Users to Die At Home: Palliative Care For Vulnerably Housed And Homeless

Individuals

Master of Social Work, 2017

Taggart Archer

Program of Social Work,

Ryerson University
\end{abstract}

The current climate of death, dying and access to care is evolving on a daily basis. As community resources and shelters within Toronto are being revitalized, the demand on the healthcare system continues to increase. This study explores how an interdisciplinary community healthcare team is challenging the current model of palliative care for service users who are vulnerably housed or experiencing homelessness within Toronto. Specifically, I am looking at understanding strategies of resistance to receiving a one size fits all form of care. This qualitative design used interviews to speak with five healthcare workers who work within an interdisciplinary care team to support this population. The outcome of the study highlights the experience of the participants regarding the importance of an interdisciplinary team approach to care, the resistance embodied within practice and the field, barriers to care and the challenges of the role. 


\section{DEDICATION}

I see the effects daily of a life limiting illness. The power of the individual and the strength of those around them. Thank you to my beautiful Mom who exhibits daily what strength and survivorship is. Thank you to my Dad for being a truly incredible caregiver and partner.

And to everyone else in my life thank you for supporting me through this hellish year. Without each of you, those extra letters would not be possible.

Thank you to each participant, your work and dedication continues to inspire me daily.

Kiss my ALS 


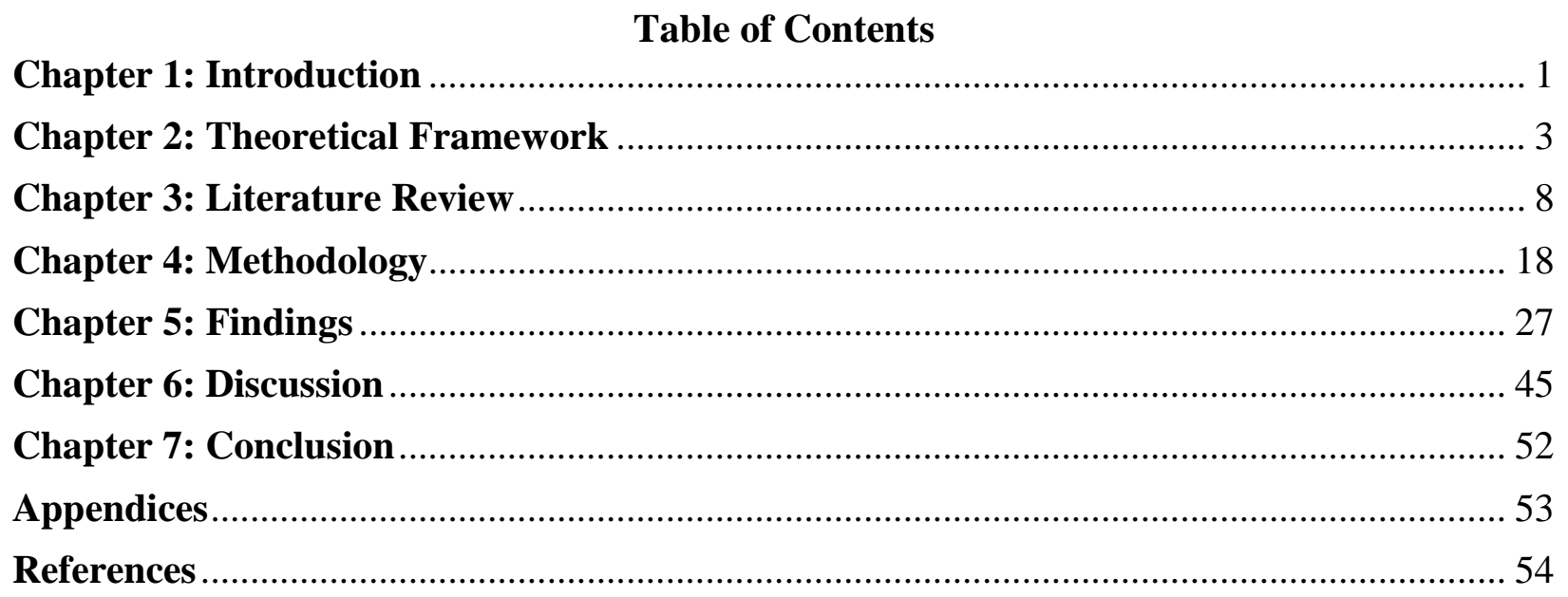




\section{List of Appendices}

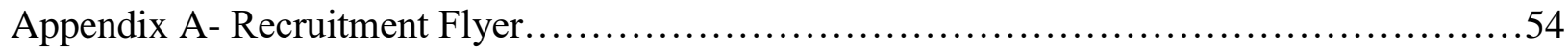




\section{Chapter 1: Introduction}

Looking at the current climate in Canada and more specifically Toronto, every day the landscape changes; condos are being built, community housing is getting remodeled, and areas are revitalized. These projects of revitalization have a direct impact on marginalized communities including those experiencing homelessness and vulnerably housed individuals. There is an increase in the current conversation and revitalization of the Toronto downtown core. It is evident that this has caused a push to move the homeless and vulnerably housed populations out of the core. The goal of this push is to make room for economic growth and wealth for corporations. The Ontario Coalition of Poverty has discussed their concern about the revitalization of the Toronto downtown core saying "Poor people are being pushed out of the downtown core. The redevelopment of George Street is a major step towards the elite consolidation of our downtown" (OCAP, 2015). Specifically, the revitalization centred around George Street which includes the closing of Seaton House, which is one of the largest male shelters in the city with approximately 500 beds including palliative care beds. It was originally thought that the demolition of Seaton House is to make way for condos and student housing. However, since the approval of the George Street revitalization plans, the area is set to include 378 beds in a long-term care home emergency shelter with 100 beds for men, 21 units of affordable housing, transitional living with 130 beds, and a service hub (City of Toronto, n.d.). Regardless of the plans that include continue supports for homeless and vulnerably housed individuals, the number of beds in the proposed plan do not match the current numbers of Seaton House. Despite the revitalization there is little dialogue about who these changes are impacting and the possible negative outcomes. Reflecting on this ongoing push to move poverty out of the city, it is important to look at marginalized groups that are impacted by these changes. One of 
these groups includes individuals with a palliative diagnosis who are vulnerably housed or experiencing homelessness and their access to palliative care.

The continuous removal of services and the limited access to safe and supportive palliative care and hospice facilities have left a gap in healthcare service models. To better understand the needs and the gaps within services, it is beneficial to look at the work being done at the community level. Supporting an individual with end of life planning and symptom management is challenging on its own; adding another identity of being vulnerably housed can have a direct impact on their care and their ability to die as they have chosen. One way to better understand the barriers that are in place within the healthcare setting is by speaking with members of an interdisciplinary healthcare team working collaboratively to provide support and autonomous care for homeless and vulnerably housed individuals with a palliative diagnosis. Within Toronto, there are interdisciplinary healthcare teams that are challenging the current model of palliative care, by incorporating the voices of marginalized community members and attempting to understand what changes still need to be made. This work being done is important to further understand the best ways of supporting an all-inclusive form of care.

This major research paper will look at the theoretical framework of post structuralism, existing literature review, methodology of phenomenology, and the firsthand research that was conducted through interviews with service providers who support individuals that are homeless or vulnerably housed with a palliative diagnosis. These interviews will inform the findings and discussion section of the paper. 


\section{Chapter 2: Theoretical Framework}

Prior to understanding and dissecting the group providing support to this population, it is important to understand who the population is that they are supporting. Additionally, it is important to understand why the terms "homeless" and "vulnerably housed" are being used in the context of their work and to clearly define their meaning. Often times, a lack of stable housing can be a fluid process for people who are experiencing it. This is a result of individuals going in and out of shelters, living on the street, couch surfing, or residing in temporary housing like halfway houses. Due to this fluidity, it is important to understand the difference between homelessness and being vulnerably housed as well as how they can change on an ongoing basis. As per the Canadian Homelessness Research Network, they define homelessness as; ...the situation of an individual or family without stable, permanent, appropriate housing, or the immediate prospect, means and ability of acquiring it. It is the result of systemic or societal barriers, a lack of affordable and appropriate housing, the individual/household's financial, mental, cognitive, behavioural or physical challenges, and/or racism and discrimination. (Canadian Observatory on Homelessness, 2012, p. 1.)

Within the context of other studies which looked at people experiencing homelessness and who are vulnerably housed, they have defined vulnerably housed as ".. as those who lived in their own room, apartment, or place but had been homeless in the past 12 months and/or had moved at least twice in the past 12 months" (Sumalinog, Harrington, Dosani, \& Hwang, 2016). By defining the terms that are being used, it can be more clearly understood that there are multiple factors and power structures influencing these identities and thus influencing the care and services they will receive. 
When looking at an interdisciplinary team, it is important to understand the power structures that exist within it and how these structures influence the team's ability to provide care and support the service user. When attempting to understand how power structures are produced, the framework that is being utilized is post-structuralism. As a deconstructive technique, poststructuralism can be defined as, "a theory, or a group of theories, concerning the relationship between human beings, the world, and the practice of making and reproducing meanings" (Belsey, 2002, p. 5). The philosophy of post-structuralism began in the 1960's and emerged from structuralism (Williams, 2005). Structuralism looked at the connection between culture and the overarching societal structures. When understanding the difference between structuralism and post-structuralism, the term 'post' in post-structuralism does not mean after structuralism, but rather it means "with but also different" (Williams, 2005. p. 25.). Post-structuralism can be seen as a more radical version of structuralism in the act of working within the power structures to resist. Post-structuralism can work against hidden or overt violence in values and thus has the ability to resist and work in contrast to normalized realities (Williams, 2005). Post-structuralism does not reject these realities, but rather it works within them to disrupt preconceived ideals (Williams, 2005). Within the context of homeless and vulnerably housed populations, this is a community that faces stigma and discrimination based on their lack of access to stable housing. The issue surrounding homelessness is never seen as problem with society, the economy or the political climate, rather it is as seen as a problem with the individual for not having stable housing and thus negatively impacting the community (Kawash, 1998). These assumptions can be seen as hidden violence in values that much of society possesses, thus there is a need to resist these ideas and combat them, to provide a voice to why individuals are homeless or vulnerably 
housed and the struggles they face. Particular to this research is the importance of receiving adequate access to healthcare.

This research topic of palliative care and being homeless or vulnerably housed focuses on understanding social groups and how they change, as well as understanding the process that creates the change (More, 2013). In the context of this research, the focus will be on discovering the healthcare workers' experiences first hand rather than an outsider explaining what they think the skills and role require to be effective.

There is limited research surrounding professionals providing support for people experiencing homelessness or who are vulnerably housed with a palliative diagnosis. The majority of research (which I discuss in the next chapter) centres around either having a palliative diagnosis in isolation from housing insecurity or end of life planning as a result of an individual being homeless or vulnerably housed with a focus on understanding the social group and the impacts of change in their lives (Ko \& Nelson-Becker, 2014; Krakowsky, Gofine, Brown, Danziger, \& Knowles, 2013; Leung, Nayyar, Sachdeva, Song, \& Hwang, 2015; Lopez \&Willis, 2004; Martins, 2008; McNeil \& Guirguis-Younger, 2012; McNeil, Guirguis-Younger, \& Dilley, 2012a; McNeil, Guirguis-Younger, Dilley, Aubry, Turnbull, \& Hwang, 2012b; Partis, 2003; Podymow, Turnbull, \& Coyle, 2006; Song, Bartels, Ratner, Alderton, Hudson, \& Ahluwalia, 2007a; Song, Ratner, Bartels, Alderton, Hudson, \& Ahluwalia, 2007b; Song, Ratner, \& Wall, 2010; Song, Wall, Ratner, Bartels, Ulvestad, \& Gelberg, 2008; Sumalinog et al., 2016). However, by using post-structuralism as the theoretical framework, I am seeking not only to understand the population of professionals providing care and their motivations but also to understand the structures that influence the care they are able to provide, acts of resistance within their work, and the outcomes of their work. 
Consequently, because post-structuralism as a theoretical intervention uses a critical lens, it has the ability to apply an anti-oppressive framework as an overarching theme to the research. It is said that post-structuralism embodies reflection and critique of practice and theory, thus it builds more multifaceted ideas to trouble or contribute to practice (Wendt, \& Seymour, 2010).. Thus by having post structuralism as the predominant framework and having ant-oppressive practice as an additional lens, it has the ability to challenge power structures, use a critical lens while keeping in perspective additional oppression. When understanding what anti-oppressive practice means with respect to research, it can be understood in the following way;

Anti-oppressive practice orientations within research offer a lens by which analysis of the worldview, assumptions, and motivations of the researcher can occur. The researcher pays attention to their experience and understanding in relation to power dynamics, and in particular privilege (Baines \& Edward, 2015, p. 28 ).

By having an anti-oppressive practice lens analyzing power dynamics, worldview and privilege, those notions can be linked to what post-structuralism seeks to unearth and expose. I understand this exposure of these structures is the basis of post-structuralism. In using post-structuralism as a theoretical framework, this research will aim to discover how the structures like the healthcare system affect this populations practice as workers as well as the service user.

One of the philosophers of post-structuralism was Michel Foucault who said "this then is what needs to be done. It should be an instrument for those who fight, those who resist and refuse what is" (Foucault, 2011, p. 84). Within the context of post-structuralism and the act of resistance, Foucault describes using it as a tool to counteract the authority that certain concepts are thought to be true and others to be false (Harris, 2001). Foucault was noting the incorporation of resistance and critique within the theoretical framework of post-structuralism. It can be said 
that an act of resistance is the use of anti-oppressive practice and the incorporation of that framework. Understanding the connection between power and resistance and how they are intertwined is important when looking at post-structuralism as it examines the issue from all sides; "poststructuralism advocates spontaneity, fluidity and openness in political movements of resistance; the revolution of the folding in of limits extends into revolutionary structures and goals" (Williams, 2005, p 20). This means when using post-structuralism, it not only works within the structures of power but incorporates resistance within it which highlights movement between the two and how they are connected to expose power.

However, it seems that post-structuralism almost has a form of anti-oppressive framework embedded within it unlike other theoretical frameworks used when researching this population. As post-structuralism embeds resistance and critique within the theory, it mirrors many of the same principles as anti-oppressive framework theory. Hence when looking at the work healthcare providers are doing within the population of vulnerably housed and homeless population these ideals are emulated. Therefore, when choosing to examine a Toronto-based interdisciplinary healthcare team, the approach best used is one that would help to examine the power structures that are embedded in their work, understanding the population and their lived experiences, the structures that may hold them back from providing care but also to interpret ways the team practices overt or covert forms of resistance within their practice to support service users. 


\section{Chapter 3: Literature Review}

Research that looks directly at palliative care/death and dying for homeless or vulnerably housed individuals is limited. Often the research focuses on end of life planning for service users with a palliative diagnosis. This focus may be because individuals who experience homelessness are disproportionately at a higher risk for multiple illnesses; this is largely due to their environment increasing their vulnerability to illnesses ranging from infectious diseases, chronic illness, mental health issues, or addiction (Sumalinog et al., 2016). Thus, the need for end of life planning is important due to their vulnerability to illness resulting in death but the research has missed those with an end of life diagnosis who are homeless and vulnerably housed. Furthermore, much of the literature looks at how a dual diagnosis can also impact the type of care homeless individuals receive and if they are willing to accept service (Song, Wall, Ratner \& Bartels, 2008). Some of the overarching themes within the literature include the notion of a good and bad death; relationships with healthcare workers, education for workers, quality of care, harm reduction, and environment of care, which I discuss below. I end this chapter with a discussion of the gaps in the literature.

\section{Good and Bad Death}

Much of the literature centres around the notion of achieving a 'good death' for the homeless and vulnerably housed population. The focus was on defining and understanding what a good death is and how it can be achieved. The concept of good or bad is subjective to the individual, but the literature highlights some common themes specifically regarding symptom management, respecting an individual's choices regarding their burial, and the idea of being unnamed/unidentified after death (Ko, Kwak, \& Nelson-Becker, 2015; Song et al., 2007). The aim of any palliative care agency or hospice is to provide round the clock, intensive care and 
support, yet often that marker of what service users described as a good death and thus good care is not being met, or there is an assumption that it cannot be fulfilled (Ko et al., 2015; Payne et el., 1996; Song et al., 2007a). Therefore, by examining an interdisciplinary community health team that is thought to be providing exceptional care according to the medical and homecare community professionals, it would be beneficial to examine their strategies and tools that other organizations may be missing. Specifically looking at end of life care with regards to who gets to make decisions and what support is available, agencies often do not have the ability to meet the demands; for example, many participants lacked family support and thus needed to create alternative routes of decision makers as needed (Ko \& Nelson-Becker, 2014). This theme of secondary decision makers and the instability of family left many homeless and vulnerably housed individuals lacking supports when it comes to end of life decisions. This lack of support is what geared much of the research to look at advanced care directives and end of life planning in general. The thought was that if individuals had the opportunity to plan out their wishes for their health and end of life plans, it would relieve stress and anxiety related to their death (Leung, et al., 2015).

\section{Relationships with Healthcare Workers}

Relationships can also affect end of life planning between a service user and their workers. The relationship of workers and the service users was often discussed as challenging and one that lacked support or understanding. A recurring theme for homeless and vulnerably housed participants with regards to palliative care or end of life care planning is a feeling of mistrust towards healthcare professionals and the healthcare system in general (Krakowsky et al., 2013; McNeil \& Guirguis-Younger, 2012; Song, et al, 2007a; Song et al., 2007b). Participants’ attitudes have been affected by the way healthcare professionals have interacted with them 
previously, and thus they were less willing to seek treatment or any assistance as a result. Participants discussed how physicians and other healthcare professionals used oppressive language towards them and they believed they did not use all the same resources they could for someone who had stable housing (Song et al., 2007b). These experiences created a lack of trust, fear, and separation between participants and healthcare professionals. These feelings may influence whether or not a service user goes to hospital to seek care or calls their worker for additional community supports. By having this lack of trust or no relationships with workers, it puts additional stress on service users and can have the possibility of additional harmful experiences (Song et al., 2007b). Participants discussed the difficulty they had working with healthcare providers because they were often unresponsive or unaware of service user's needs (Sumalinog et al., 2016). This may indicate that there are barriers to communication between service users and healthcare professionals resulting from a stigma and fear felt by service users. As a result, some participants tried to separate themselves from other people who were seen as homeless to receive better care (Martins, 2008). Furthermore, some service users expressed experiencing a feeling of invisibility because often they felt healthcare providers did not believe what they were saying in regards to their symptoms or pain (Martins, 2008; Song et al., 2007b). Despite this theme of mistrust and poor relationships with workers, the research did not address how to build better relationships. There was no discussion of community outreach or other tools to begin this process. For those articles that did speak directly with the service users, it would have been beneficial to ask how they think new and trusting relationships with healthcare providers can be formed (Krakowsky et al., 2013; Payne et al., 1996; Song et al., 2010). 


\section{Education}

One suggestion that came from the literature was to provide educational training to both staff and service users (Krakowsky et al., 2013; Song et al., 2007a). Training should be provided for the service users about what options for care are available. Training for the healthcare workers should be provided on the topic of death and dying and then more specifically on the particular needs of the homeless population as they are vastly different from those who have secure housing (Krakowsky et al., 2013). Skills and educational training are often a helpful idea when it comes to providing care, as the needs of service users are constantly evolving. However, the studies do not take into consideration the limited funding of agencies or that they are often understaffed, and the ensuing implications for training. There was no mention of how to implement the findings of the research to community agencies to support both staff and service users in achieving a higher quality of care. However, the significance of this training appears as an overarching theme and recommendation in the majority of the research. It shows that many service users felt they have experienced or had witnessed negative interactions with healthcare workers and were treated poorly compared to any other population (Ko \& Nelson-Becker, 2014). Additional education or training for service providers would enable them to learn how to effectively support service users who are experiencing homelessness and thus begin to build a rapport with the service users. By effectively building rapport the outcomes would be positive as service providers would be able to provide a higher quality of care and service users would be more willing to receive care and support.

\section{Quality of Care}

With proper funding and staff availability, the support of a healthcare worker creates a more successful process for end of life care which reduces the stress and isolation a service user 
would face if they needed to complete this work on their own. Having a connection with healthcare workers is necessary because as discussed below, the research found that when completing end of life advanced care planning, individuals working with a counselor were more successful in completing their advance directives. Song, Ratner, and Wall, (2010) found that the completion rate of end of life advance care planning with support of a counselor was $37 \%$, and those that completed the directive on their own was $12.8 \%$ (p. 489). The study did not discuss how many staff the agency had available to work with service users to complete these directives and if staff would have the capacity to work with additional service users on an ongoing basis to achieve this success again.

\section{Harm Reduction}

The theme of education and additional training for staff is often linked to the increased knowledge and support of harm reduction programs (McNeil \& Guirguis-Younger, 2012). Many hospitals or hospice programs do not accept patients who are using non-prescription drugs due to rules within the facility; often an anti-drug policy is in place and excludes these individuals from accessing these services (McNeil et al., 2012a; 2012b; McNeil \& Guirguis-Younger, 2012; Song et al., 2008). This is another example of a barrier to care which would affect service users who are vulnerably housed or homeless as the rate of drug or alcohol use is higher than those with secure housing. Thus, service users who are vulnerably housed or homeless face an additional barrier to care which further highlights the inaccessibility to formal end of life care supports. The notion of barriers to care is something that much of the research discussed in terms of what contributes to individuals being held back from care and how agencies should be adapting policies to service users' needs. Building from the concept of adapting to service users' needs, the model of harm reduction is one that allows service users to feel more accepted and supported 
within healthcare environments. Not only does a harm reduction model help support service users but the model also effectively saves money for the healthcare system by reducing the frequency of emergency room visits (Podymow, Turnbull, Coyle, Yetisir, \& Wells, 2006). Despite the success of these programs, they are not yet the standard (McNeil \& GuirguisYounger, 2012; Podymow et al., 2006). Harm reduction may not be the standard for multiple reasons including the difficulty in changing long-standing policies, lack of training to facilitate this method or lack of community support. It is important in this research to understand how programs that incorporate a harm reduction model can be successful. Participants identified that by having agencies expand their policies to include possible practices of supervised drug use, it would improve their quality of care. Zero tolerance policies and rules around illicit drug use were created for agencies to maintain order within the facility, however, it is unrealistic for agencies to make service users change long-standing, pre-existing habits to fit policies created with the only purpose of maintaining order instead of providing care (McNeil \& Guirguis-Younger, 2012). The theme of engaging in substance use was discussed as a coping mechanism for individuals from physical pain, unsafe environments or mental health issues (Song et al., 2007b). Often times agencies forget why patients use illicit drugs or other substances, especially when dealing with end of life care. Service users often have to manage their pain and symptoms in any way they knew how while in a non-medical setting. A study that looked at harm reduction in shelters found that once participant's pain management was under control, illicit intravenous drugs used was significantly reduced (Podymow, et al.,2006).

\section{Environment}

Creating a welcoming and safe environment was another recurring theme in much of the research for individuals who do not have stable living facilities. The research found that having 
flexibility with where palliative care is provided is crucial to providing care that supports all individuals (Krakowsky et al., 2013; McNeil et al., 2012; Sumalinog et al., 2016). Having the ability to provide palliative care from hospitals, shelters, or street-based settings would allow each individual to decide the best way they can be supported (Krakowsky et al., 2013). A notion of familiarity was important to many participants who identified that they would rather remain in a shelter over moving to a hospital or palliative care facility as they felt a sense of home within the shelter setting (McNeil et al., 2012b; Podymow et al., 2006; Sumalinog et al., 2016). Despite it not being a medical setting like a palliative care unit or hospices, it offered more support specific to their daily needs. This included harm reduction practices and support from the same ongoing worker, despite their needs being beyond the facility's range of duties (McNeil et al., 2012a). This concern of a medical based setting is often linked back to the zero tolerance policies of drug or alcohol use. Medical facilities having a zero tolerance policy or requesting patients to use off-site can have negative effects like drug overdoses (McNeil \& Guirguis-Younger, 2012).By not creating an environment that welcomes all patients, it puts unnecessary stress on an already stressed shelter system and puts shelter staff in a position where they are working beyond their training and skill set. Reports have stated that there is a cost savings to the healthcare system in supporting palliative care facilities within the shelter setting if these organizations have the ability to take on this specific population (McNeil \& Guirguis-Younger, 2012). It is important to look at the notion of cost as it has been my observation from my social work practice experiences that is the focus of governments and policymakers. The result of having shelter-based care to support the palliative homeless population would alleviate stress on hospitals and emergency rooms. Despite research findings that report financial incentives for government, city planning sectors as well as positive outcomes for service users' overall well- 
being, facilities who would meet these demands are being shut down (Podymow, Turnbull\& Coyle, 2006). For example, Seaton House, which is the Greater Toronto Area's largest men's based homeless shelter that includes a palliative care unit within the facility, is set for demolition. This demolition of Seaton House and revitalization of the area comes without any discussion on the public level on how to support these service users when the palliative care service is no longer active. As mentioned this revitalization of George Street including the demolition Seaton House does not identify if or how they plan to match the 500 plus beds or specifically the palliative care floor, as well as how to not disrupt the care of those currently being housed by Seaton House.

\section{Gaps in the Literature}

One gap that was evident was that further research is required to identify additional programs needed or what programs should be incorporated into palliative care. A major theme was that many homeless individuals face other barriers such as addiction and many opt out of care due to not being able to smoke, drink or use drugs. Some programs specifically within Toronto do allow alcohol, smoking cigarettes, and practice from a harm reduction model; however, there continues to be a barrier for more recreational drug use. An important discussion of how to incorporate recreational drug use into palliative care programs while maintaining safety for all residents and staff is needed. An interdisciplinary care team has the professional ability to provide support for those who are practicing harm reduction or plan to withdraw from substance in order to receive care. Supporting a service user with this decision needs to be achieved through all angles of care, both medically and emotionally, with ongoing capacity for support. An interdisciplinary team would be able to do this most effectively and seamless due to the breadth of service and support available from a multidisciplinary team. Without an 
interdisciplinary approach to care, vulnerable populations will continue to be cast aside, and their needs will continue to not be met ${ }^{1}$.

As the current dialogue of palliative and end of life care is constantly changing and evolving, it is important to ensure that marginalized voices are being represented. As medical assistance in dying (MAID) has been passed, healthcare workers and social service workers will need to incorporate this aspect into providing care. It will be important to explore how workers will be providing this service to users who identify the streets or shelters to be their home. As the previous literature has discussed, education and training for staff will be needed to ensure they have the understanding of what homeless and vulnerably housed people are facing and the barriers to health and social supports. Themes of a good and bad death, harm reduction, and appropriate environments seem to be universal concepts to have the best care and to incorporate interdisciplinary teams. In the context of an urban landscape like Toronto where thousands of people are homeless or vulnerably housed, and the supports are disappearing, these changes affect every community member (Shapcott, 2013). A change in shelter support or palliative care within shelters could affect hospital wait times and the amount of beds available. Overall, it could be beneficial to see how successful programs that work from a harm reduction approach and client-centred model work to support individuals that are experiencing homelessness and

\footnotetext{
1 "A multidisciplinary team approach is discipline oriented, with all professionals working parallel and with clear role definitions, specified tasks and hierarchical lines of authority" (Körner, 2015, p. 746). Such teams often place the physician in the centre of authority with limited communication between the other professionals involved (Körner, 2015).

"Interdisciplinary team work is a complex process in which different types of staff work together to share expertise, knowledge, and skills to impact on patient care" (Nancarrow, Booth, Ariss, Smith, Enderby, \& Root, 2013, para 1). An interdisciplinary team works from a collaborative approach with intense communication among professionals (Körner, 2015).
} 
maintain their autonomy and dignity during the dying process. By reviewing the research, it is evident that there are key themes in the literature; good bad/bad death, relationships, education, quality of care, harm reduction, environment and gaps. Each area centres on how to effectively provide care to vulnerably housed and homeless service users. The research conducted within this paper looks at how to achieve effective care with an interdisciplinary model provides support by healthcare professions from different professional backgrounds. 


\section{Chapter 4: Methodology}

When choosing a methodology for the research, it was important to incorporate one that centred around the lived experiences of the interdisciplinary health team members and how they use their experiences and knowledge to support the service user. Additionally, phenomenology is important when looking at this population as "phenomenology contributes to deeper understanding of lived experiences by exposing taken-for-granted assumptions about these ways of knowing” (Starks \& Trinidad, 2007, p 1373). One taken for granted assumption about the role of social workers and those in health care is that they are able to support all service users and when difficulties arise it is the service use who is unwilling to work collaboratively instead of understanding that not all the answers lie with the service provider. Therefore, the methodology chosen for this intervention is phenomenology. Phenomenology is defined as, "The study of human experience and the ways things present themselves to us in and through such experience" (Sokoloski, 2000, p. 2). The focus of phenomenology is a more in-depth understanding of lived experiences that is often overlooked or assumed (Starks \& Trinidad, 2007). Therefore, the goal of this methodology when conducting research is to "describe the meaning of the lived experience of a phenomenon" (Starks \& Trinidad, 2007, p 1373).

This methodology can be linked to the discussion of palliative care for people experiencing homelessness and those who are vulnerably housed viewing homelessness and palliative care as a phenomenon. I often hear people speak about homelessness in ways that show that there are many assumptions around homelessness within a social context, which perpetuate the idea that to be unstably housed you likely have an addiction or are lazy. Conversations are usually centred on the notion of deserving and undeserving of supports; this theme is dehumanizing and continues to portray homelessness as an individual's issue versus a systemic 
problem. I also have heard many assumptions made by others about the service providers' work, most notably why they got in this role and the ease of the work. Therefore, because this research focuses on the role of the worker and not the service user we will be unpacking the assumptions about their role. Within the context of this research, service providers were asked to speak about their first-hand experiences with this population, how they work within a seemingly accessible and equal health care system.

This research seeks to highlight the injustices embedded within the health care system, other policies and society more generally, which make it difficult for them to successfully complete their job. In doing so, I hope to expose and challenge the public narrative of a worker in the community serving homeless and underhoused people who are terminally ill. Phenomenology attempts to counteract these preconceived narratives by attempting to remove previous assumptions about the phenomenon focusing on embodied experiences and thus allows the community behind the phenomenon to create an authentic narrative (Partis, 2003). For this research, this methodology was chosen as it removes barriers from the researcher and centres the voices of the population (Starks \& Trinidad, 2007). Additionally, phenomenology focuses on the common aspects of the lived experience even if the participants may highlight different experiences, as the focus is to extract the heart of the phenomenon to uncover the experience (Starks \& Trinidad, 2007). This will become clear in the findings of the participants, where we can see that they each carry out a different role but have the same goal of supporting a client with a palliative diagnosis who is homeless or vulnerably housed (Starks \& Trinidad, 2007). Thus, these workers provided a broader range of experience but the commonality of their goals highlights the lived experience of the worker as the phenomenon. 
When using phenomenology as a methodology, it can be used within the context of either a descriptive or an interpretative approach. In the context of looking at an interdisciplinary team that supports the population of homeless and vulnerably housed individuals with a palliative diagnosis the approach that will be used for this focus is interpretive. However, to first understand the interpretive approach one has to understand descriptive phenomenology as interpretive emerged from it. Edmund Hussrel is often referred to as the founding father of phenomenology (Gallagher, 2012). Hussrel brought about the approach of descriptive phenomenology; this approach believes that human experience is as important as scientific fact (Loez \& Willis, 2004). Descriptive phenomenology centres around the researcher 'bracketing' their prior knowledge and ideas as much as possible, towards achieving 'transcendental subjectivity', wherein the research is focused on describing the meaning of the experience in its purest form; that is, the researcher's biases and previous knowledge of the area of study are continuously assessed to ensure they do not influence the findings of the study (Loez \& Willis, 2004).

A student of Edmund Hussrel, Heidegger built upon these ideas of descriptive phenomenology and created the interpretative approach (Loez \& Willis, 2004). The interpretive approach centres around the question of how does someone's personal narrative impact on their everyday experiences (Loez \& Willis, 2004). One of the key principles to Heidegger's approach to phenomenological inquiry was what he referred to as 'lifeworld' which he defined as "to express the idea that individuals' realities are invariably influenced by the world in which they live" (Loez \& Willis, 2004, p. 729). Therefore, the question that is posed when looking at the interpretive approach within the context of Heigdegger's term 'lifeworld' is how do individuals, experiences, and their interpretations of their experience contribute to the similarities and 
differences within a particular role. Thus, the discussion will be centred around understanding the experience of the worker, of what it is like to provide palliative care to homeless and vulnerably housed service users and what it is like to take on this role. This will be done by centering the participant's voice and experience to understand how they place meaning within their role.

The day to day to routine of service providers and their motivation for doing this work are important areas to explore to understand the essence of their experiences, and is being done using a phenomenological methodology to drive the interview process and thus the research. This understanding of the motivation of their day to day work is important as we (social workers or community members) may be aware of their role but we do not understand it; the interviews will aid in understanding the essence of the work and challenging our assumptions. Additionally, phenomenology promotes interaction between the participant and the researcher to gain the deepest insight into their experience which will aid in unearthing each individual's experience (Verschueren, Berends, Kool-Goudzwaard, Huigenbosch, Gamel, Dingemans, \& Meijel, 2015), thus achieving a deeper understanding, having the ability for the researcher to be reflective of their role, and exploring why/how service providers engage in the work - all of which will assist to expose their experience.

Using a methodology of phenomenology to inform the research will aid in examining the lived experiences of the interdisciplinary healthcare team that supports this population on a daily basis. It will assist in looking at everyday life events and modes of practice to understand the meaning behind their strategic practice. Within the current research regarding the homeless and vulnerably housed population, there is very little research that looks at those with a palliative diagnosis and the role of the healthcare professional who supports the individual. 
The goal of this research is to understand the essence of the experience for the participants surrounding their role in providing effective care, outreach, and support, to service users experiencing homelessness and/or that are vulnerably housed. It will attempt to accomplish this by specifically examining interdisciplinary approaches to care, relationship building with service users and adapting to the changing landscape of Toronto and services available to support the service user. The aim is to learn from this interdisciplinary care team's experiences in sharing their role in hopes of gaining a deeper insight into their exemplary care for this specific population.

Phenomenology as the methodology informs the research, and is supported by the method of interviews. The research focuses on an interdisciplinary team within the healthcare field of palliative care; the research will explore how their team differs from the majority of care models within healthcare institutions, how they use the lived experience of the population to inform their care practices and how they work from a client-centred and autonomous approach. Recruitment was done within one healthcare agency; the Toronto Central Community Care Access Centre $(\mathrm{CCAC})^{2}$. The Toronto Central CCAC has an interdisciplinary healthcare team that supports service users who are homeless and/or vulnerably housed with a palliative diagnosis. This team was chosen as they are at the forefront of care and are working in the community to support this population. In addition to requiring research ethics board approval from Ryerson University, in order to conduct research within this organization an application to their research ethics board was submitted. The process was extensive and took approximately three months to have everything finalized and approved by all parties including the research

\footnotetext{
${ }^{2}$ At the time this research was being conducted the Community Care Access Centre was absorbed by the Local Health Integration Network (LHIN). The Toronto Central CCAC is now referred to as Toronto Central LHIN.
} 
ethics board and the managers of the teams involved. The final step in the ethics approval included having two managers within the organization sign off on the research in order to contact the staff. After meeting with both managers and receiving approval from their Ethics board I was able to send out the recruitment flyer to the team (Appendix A). An initial email was sent to the manager informing them of my research and attaching the recruitment flyer Staff was then able to contact me directly in order to arrange an interview.

This qualitative design used the method of interviews; the interviews were in-person and were conducted in a semi structured format meaning that all participants were asked the same set of question but as topics emerged from responses, additional questions outside of the preset questions were asked (Wilson, 2012). The method of interviewing was chosen for data collection as it is one of the leading forms when using phenomenology (Bevan, 2014). Engaging in long interviews allows the time and space for reflection and deep exploration by the participants, which is essential to understanding the essence of their experience (McCracken, 1988). Additionally, as previously mentioned using phenomenology allows more discussion between participant and interviewer to expose the experience. Using a semi structured interview guide allows for this dialogue and discussion to occur during the interview process; if a structured interview was conducted there would be no room to probe the participants for more information or push for a deeper understanding of their experience (Brinkmann \& Kvale, 2015).

Questions for the participants focused on understanding their role which they are providing to service users, understanding the gaps and barriers for both service user and worker, and also understanding the landscape of palliative care for homeless and vulnerably housed individuals. Within the recruitment flyer, it was estimated that interviews would take between 1 to 1.5 hours, however, after completing the interviews none of the participants went over the 
hour mark. The questions included gaining a very basic understanding of the work and their role by asking them to describing a typical work day, their motivations to work in this field, how do they build rapport with this specific population. Then the questions narrowed in on the difficulties of the role and the challenges that are faced by healthcare workers and services users that the Toronto landscape presents. To reiterate the focus of the questions were on lived experience, to be able to explore differences and highlight similarities between workers that emerged in the interviews, given my focus on a methodology that seeks to understand the lived experience of the subject and not draw preconceived conclusions.

The interview process took place in a two-week time period. Each interview was conducted at the times most convenient for the participant as they work in the community and their schedules are full and can change on a moment's notice. Interviews were arranged directly with the participant; a copy of the consent was provided prior to the meeting and then signed and discussed prior to the interview as needed. Before the interviews were conducted participants were also given a copy of all the questions and informed that some clarifying questions may be asked or other questions may emerge, asking them to expand on certain topics that are brought up as needed which would not be on the list of questions in front of them. All participants were receptive of the questions and expressed their importance and made them think critically.

Prior to recruitment, the study went through two research ethics board to receive approval to interview service providers - Ryerson University Ethics Board and the organization's own ethics board. In total, this was process was about a three month process to receive approval from both research ethics boards, which was originally not budgeted in the timeline of the major research paper. However, the final approval for the project came at the end of June 2017 and recruitment began immediately after that. The initial expectation prior to recruitment was to have 
between 3-5 participants; the inclusion criteria to participate in the study was a healthcare worker with the role of care coordinator, physician, nurse practitioner, community nurse, or any other provider who supports homeless and vulnerably housed individuals with a palliative diagnosis. The data for the research was collected over the course of a two-month time period from June 2017 to July 2017. Initially the interest seemed low after the recruitment flyer had been distributed within the palliative home care community with only two participants agreeing to be interviewed. The research would have been limited with only two participants; however, it still would have been possible as it would have given voice to the lived experience of those particular service providers. Thankfully a third participant contacted me and during that interview it came to light that two additional service providers had reached out to be part of the project. These emails were not received however, because two of the participants were using an inactive email address of mine to express their interest. In the end, a total of five participants were interviewed for the project.

After transcribing each interview, I had initially prepared to use NVivo software to analyze the data. However, I found it to be cumbersome as you needed to use the computer and seemed to be very similar process to analyzing the data manually. There seemed to be no clear advantage for using the software compared to working manually through each transcribed interview. Therefore, for data analysis I used a manual process and went through each question or paragraph and applied a theme to it. Some sections had multiple themes and others only had one. Initially the process of finding connections and themes was just based on the way the interviews were structured. This ordering process left many sub themes with no overarching concept, thus the next process to better order themes and connections was to cluster themes. This can be envisioned as Smith and Osborn suggest whereby you "Imagine a magnet with some of 
the themes pulling others in and helping to make sense of them" (2015. p. 70). For example, when themes like 'grassroots', 'organic' and 'creativity' emerged in the interviews within multiple participants stories, it was easier to understand them under the classification of resistance, especially given that I had clarified the concept of 'resistance' with the participants during the interviews. This process of clustering helped to group participant discussions under categories to ensure they were representative of each other. . Prior to the analysis even after the second interview I could see similar themes and experiences emerging as participants shared experiences and thoughts. The analysis process was challenging as some of the participants spoke in great detail about larger concepts and not specific to the question or their role. However, even when the discussion moved in a less linear process the content was rich and informative. Overall, phenomenology was chosen to honor and respect the work being done by each participant, to be able to explore the meaning of their experiences. To share their voice and experience of their work, this was done by highlighting their experience and giving them a voice and space by choosing interviews for the research. 


\section{Chapter 5: Findings}

This chapter will explore the interviews conducted with five healthcare professionals who are working in the Toronto community with service users who are vulnerably housed or homeless. The workers volunteered to participate in the interview as they identified that they have experience with this population. All participants are part of an interdisciplinary healthcare team that is leading the way for community based supports. The participants ranged in their educational backgrounds; from social worker, nurse, nurse practitioner, and physician. Each participant came from a unique background either working solely with homeless or vulnerably housed service users with a palliative diagnosis or working with both those with secure and insecure housing. Despite their differences in their level of involvement with this population, they are all working at the community level to provide care and effective support. Before introducing the findings that were unearthed during these one on one interviews, it is important to know the voices behind the knowledge that is being shared.

Participant one (P1) is a social worker by background working in the community with service users as they described with "life limiting illnesses at various stages". Their work has predominantly been supporting service users with more stable or permanent housing. However, P1 said that their work has included supporting those who are marginally housed such as service users in shelters, those without status dealing with deportation issues, and those with insecure housing.

Participant two (P2) is a nurse practitioner by background working in the Toronto community. Within their role, P2 identified that they work with both clients with stable and insecure housing, they have supported clients who are uninsured, undocumented, sofa surfers, 
and who are generally precariously housed. Their role is to work with service users in the community while they provide primary care and support.

Participant three (P3) is a nurse by background who works to support service users housed and those marginally housed. Their work has supported those who are or have been street homeless, shelter-based, non-status and other forms of being marginally housed.

Participant four (P4) is a physician who works with both street and shelter-based service users. P4 entered into this work in what they described as a very "organic" and "emotional response" to what they were seeing in the community.

Participant five (P5) is a nurse by background who works at the community level with both street and vulnerably housed service users within Toronto. They described their role as focusing on "healthcare navigation" to help support users within a very complex healthcare system.

All of the participants work within an interdisciplinary care team to support this population; however, their role is unique as it is a very specific population that faces various challenges and barriers that service users with a palliative diagnosis who have a permanent address and are stably housed do not face. The participants highlighted several themes throughout their interviews. These themes help to understand how their work is at the forefront of palliative care and what they believe are area of improvement then can be made. Themes such as the interdisciplinary care team, resistance, and equality and equity of care arose throughout the interviews.

\section{Interdisciplinary Care Teams}

One significant theme that was brought to light was the importance of interdisciplinary support in order to provide palliative care. This is a team that works in collaboration with other 
community agencies in order to provide the most effective care possible. Depending on the agency, professionals and other providers often work in silos (in isolation from one another, not communicating directly, and providing less of a well-rounded approach to care) in order to provide care which is not necessarily the most effect approach to supporting a service user. This can negatively impact the individual's care plan as they are not supported from all areas. In the case of these professionals interviewed, they work both directly and indirectly with many types of workers including, but not limited to personal support workers, nurses, nurse practitioners, occupational therapists, physiotherapists, shelter staff, case workers, doctors, palliative care physicians, care coordinators, managers, and administrators.

All of the participants take part in teleconferences frequently either every day or particular days depending on their workload. During these teleconferences workers can provide updates on a client's status and changes to care plans. Generally, it is front line staff like nurses and personal support workers reporting in while the other workers take note of these changes as it relates to their specific role with the client. P1 described these workers as, "the key part of my job, they are the eyes and ears in the home, they're the one providing the hands-on care". This idea of the extended team being the eyes and the ears in the home or the community was echoed by P3 who identified that they rely on those in the community heavily to update them on service user's constantly changing statuses

I actually rely on the nurses in the community, the physicians in the community so that I can know if a client's condition is changing if I need to add an additional supports or ya just for updating me on clients status so that I know how I can support them at that time. (P3). 
Without an interdisciplinary model of care P2 identified they would not be able to see as many patients without the support of the team, saying "it would be much more cumbersome and take more time and much more ineffective so I'd probably be able to see far fewer patients then I manage now". These relationships that are formed with care providers also extend to the service users. Many participants talked about the difficulty of building trust and rapport with clients because of the service user's previous experiences with other healthcare workers or organizations. P1 discussed the difficulty of building trust and what can be done to begin to create a rapport and positive relationship,

when we are not be able to build that trust we borrow the trust from staff members that have been there longer so without those staff members trusting us first allow us to borrow that trust to connect with the client (P5).

This statement exemplifies the importance of interdisciplinary care teams, wherein the work cannot be done alone, providers cannot have a positive relationship with every client, and to recognize that it is not possible for every provider to be able to connect with every client. This is why having the support of a team whether it be a collaboration with another organization or within the organization is crucial in establishing proper trust and rapport. P3 spoke about a success they've had because of the interdisciplinary care team approach, they said,

We had a client that was going into hospital every single day and I got this email from this emerg[ency] department saying 'this is amazing he hasn't been here in a month.' And like that's like such a huge victory like for somebody who used an ER daily and now because of this intervention which is you know getting him appropriately housed with like the right services and follow up... ya it's been amazing (P3). 
This statement highlights the importance of community-based supports that this service user has had, because they are connected with the team, that they are able to have supports like personal support workers, nurses, nurse practitioners, nursing coordinator, care coordinator, and physicians. This not only can be a success for the team or the hospital but also more importantly the service user that their pain and symptoms are being managed.

\section{Resistance}

One very pivotal moment within the interviews was when P4 discussed the history of palliative care and how it was a grassroots movement, the origins of this type of care like hospice is a relatively new form of care starting in the 1950's. They described palliative care itself as, "palliative care/ palliative medicine is a grassroots entity. It came from the grassroots a bunch of advocates who advocated for change in how we do things..." (P4). This is important to note because in essence the act of palliative care was a form of resistance to the landscape of medicine and patient care. It was something that providers saw as lacking and needed to occur in order to provide a more effective care for individuals to die with their pain and symptoms being managed correctly and their other needs being met. P4 went on to say, "we are grassroots people at heart whether we recognize it or call it". This statement was powerful not only because it shed light on the work that is being done but also because it recognized that the act of supporting service users with their palliative care needs is a ground level action, a community action that occurred to fill a gap that existed. This is particular relevant because one of the questions posed to each participant was if they are able to practice resistance within their role. Despite P4 alluding to the fact that palliative care stemmed from grassroots movement and thus could be interpreted as an act of resistance in and of itself. When participants were asked if they practice resistance in their work and how they incorporate it every participant asked for clarification in 
what was meant by resistance as they had never heard it in that context. Throughout the interview many of the participants discussed particular aspects of their work where they had to get creative in the system, and use specific tools and allies to support the service user. Actions like collecting left over supplies to provide supplies to service user who did not have OHIP, bringing coffee and donuts during meetings to build rapport, moving furniture for clients as they had no other personal supports, are only some of the examples they discussed when talking about their role. Not once did any of the participants use the word resistance. When asked if they are able to practice resistance within their role P1 said "I wouldn't have called it resistance but I think we have to be very creative."

There was no collective word used by all participates to identify the strategies and tactics of resistance that they use in their role. Despite of the term resistance not being their initial descriptive word for their work, each service provider discussed how this term was applicable to their role and supported the way they practice as professionals.

These acts of creativity / resistance that they are incorporating to drive their work within a social work educational framework would appear to be acts of resistance. These conscious or unconscious efforts made by the provider appear to be the intent behind their work. P5 described this by saying,

We have to be creative we can't... allow the system or a job description to define what we do because then it's going to be within the system that constraints that this population has always experienced (P5).

Many care providers are unable or are unwilling to go beyond their role to provide the care that service users require. P3 talked about this difference of going beyond the workers' role on paper, saying, 
our service providers you know if they can't get a hold of client they are not going to do a visit and for us you know we also know where they hanging out like if they not at home they are at a coffee shop or you know they are at the bus shelter or something like that (P3).

P5 discussed this notion of meeting the participant where they are and not saying no simply because it does not match up with their job description. "That whole piece around trust building trust and rapport it's because we aren't going to say oh well we can't do that" (P5). Not automatically saying no because of job title or description is not only an act of resistance but a direct correlation of trust being built between service users and service providers.

It is important to recognize that many front line workers like community nurses and personal support workers do not carry the same power and privilege as those being interviewed. In many ways, these workers' acts of resistance are embedded in their privilege of being supported by a large organization, their education and their overall status as professionals. They use this privilege in order to enact these acts of resistance through planning, creativity, and work in order to provide effective palliative care. Additionally, other participants spoke about resistance in the form of supporting a client's choice around substance and alcohol, saying, "We had a client who huffed paint and there was like a plan to you know be able to support that by getting the client outside but ya a lot of workarounds" (P3). This highlights that often harm reduction can be challenging and in order to respect a person's decision to continue to use a substance, it has to be carefully thought out within institutions. This planning and support is needed as substance or alcohol use may not be supported within an institution where the service 
user resides or their use could be harmful to other individuals within the institution. Thus, instead of telling someone to stop their use or leave, this worker discussed the ways they resisted policies to ensure a service user gained supports and was able to continue to use as their decision.

When speaking to each participant it was clear that they have all gone above and beyond their expected roe and duties for service users, and have been blocked by the overarching systems but were able to use their skill set to achieve a positive outcome where the service user was respected, heard and validated in their choices and needs. Resistance itself within an organization is either supported or hindered within the bureaucracy of an agency and thus it requires the actions of one or many to push past the red tape either in plain sight of those who put it there or sneak under the red tape going unnoticed.

\section{Equity and Equality}

The last major theme that emerged was the participants attempt to work from a place of equity instead of equality. Some participants talked specifically about the challenges of providing equitable care and others discussed the idea without naming it. This concept links directly with the discussion around resistance and covert acts of resistance the workers have participated in. Often times when people think of the Canadian healthcare system we think of 'free' care for everyone; this thought may be because of news and other media sources that talk about the inaccessible and expensive system in the United States. However, these concepts of free care for all is often a misconception of the Canadian healthcare system. Within homecare and palliative care, assessments are done for each service user and then they receive a certain amount of personal support work or nursing. There is a maximum number of hours and types of services that can be provided based on diagnosis and needs due to funding allotments. 
When it comes to arranging end of life care such as long term care facilities, hospices and palliative care units, it can be increasingly difficult for workers to get the service users who are vulnerably housed or homeless accepted into a facility compared to those with stable housing. This difficulty stems from the effects of mental health and addictions issues within this population and as a result of these other comorbidities it can be challenging for them to be accepted into facilities. With zero tolerance policies to drugs and alcohol and with policies embedded into facilities about behaviors it would automatically exclude some service users. P4 talked about this by saying,

it's crazy to me how much we actually do fight to get people access to a bed, how loud and vocal we have to be meanwhile other people umm you know they just...they just put in papers and get accepted (P4).

This point suggests that everyone technically has the ability to be accepted into palliative care units and hospices as beds become available but the patient that is accepted looks a particular way. A service user who does not have any visible mental health or addictions issues, has family supports and will be compliant with rules and policies of the institution is more likely to be accepted into palliative care. This exemplifies the idea of equality within healthcare that appears to have many technicalities embedded within it and does actually reach all those who require access despite being open to everyone. However, providers are fighting and strategizing around ways to get homeless or vulnerably housed service users into palliative care facilities and other support services. Despite on paper having the same palliative diagnosis as other service users, they are often rejected for not meeting agency requirements. P3 discussed the difference in the service users who have secure housing and those who are vulnerably houses, saying, 
they [vulnerably housed/ homeless service users] are so resilient that they're up walking around and then the next day they are gone and that time period where their... other clients would be bed bound for a prolonged period of time (P3).

Often times agencies will use homeless and vulnerably housed services users' resiliency to their advantage by denying them a bed because they do not appear sick, despite having a palliative diagnosis. Agencies are denying service users who would be more challenging or not an ideal patient thus segregating and denying those who would prudently challenge their zero tolerance policies - a direct contradiction to the notion of equal access to health care.

Additionally, P4 explained their desire to live in a world where systems practiced from a place of equity, as people face systemic and historical oppressions that have left them marginalized and in this particular case homeless or vulnerably housed. P4 argued that there's a need to look at the system differently,

I think we are pretty good, in Ontario and even Toronto delivering the world that's based on equality giving people the same things to be happy and healthy but where we really struggle and the world I dream of living in is a world where people are focused on equity, where people get what they need to be happy and healthy and the recognition that there are some people who are marginalized and vulnerable and who are structurally vulnerable so you know... are... because of their position and a hierarchical goal um.. and hierarchical layer of structures they are actually marginalized because of oppression, discrimination, racism, colonialism, um to name a few and its only when we are able to recognize our own biases and our own... um... our own discrimination that we are able to recognize the needs of this population and the other thing to think about the kind of change I really wish to see in this world (P4). 
Saying that everyone has access to healthcare does not take into consideration the heightened needs of some individuals and the external factors that influence their needs. For example, there may be two palliative clients, where one is housed and one is insecurely housed; their needs are different yet through an equality lens, they are fundamentally viewed as having the same needs within our healthcare system.

However, P5 talked about their concern over a possible idealist view of equity, saying, "Equity does not necessarily mean access, just because we think we are providing an equitable service doesn't mean we are... people that are actually accessing us. And I think that's the biggest barrier" (P5). This gives rise to an important discussion about how to incorporate equity into a conversation about access, notably access to healthcare and other safety nets that support a person's health. The Canadian healthcare system is a leader within the global context of healthcare especially compared to our North American counterparts but it is evident that there are areas that could use strengthening so that it can continue to be on the leading edge.

\section{Barriers to Care}

In addition to these themes that were unearthed in the interviews around resistance, equity vs equality of care, and access, one common theme lingering under all of these discussions is barriers. Barriers to care is something every professional mentioned both indirectly when discussing their role and explicitly when asked. No matter how effective a care team is providing support to service users, there is still 'red tape' or road blocks they face when trying to arrange services and care plans. Despite the amount of change and strides that have occurred in palliative care and palliative medicine, there are still more areas that can be improved. When discussing barriers, it arose how barriers to care are impacting the service user and the care the worker are able to provide. There are systemic barriers embedded into a political system that is 
not meeting the demand of the citizens. One of those barriers that was discussed was the demand on the worker,

Often the care is spread too wide and too thin just because the resources aren't there .... The resources and palliative physicians, palliative nurse practitioner's whatever, so I have one death and get three new referrals. So the volume is getting bigger yet the resources haven't kept up with that (P2).

Despite having the support of an interdisciplinary team who is on the leading edge of palliative care, the demand is increasing which becomes challenging for the worker and the system.

Within a Canadian context, a reoccurring discussion was the lack of access to housing, income, food security, and basic necessities to health. These all related back to barriers of care; more specifically one of those factors was adequate housing or access to housing.

It's a huge gap, its... unfortunate that it's a gap in a country like this, you know. I go to some of these shelters, not even shelter, I go to some apartments that are social housing apartments and it just, I am just flabbergasted that we have a building like this in a country like this (P5).

Participants discussed how without housing, their ability to provide effective care can be at a standstill, with P1 saying, "I don’t think there's much more that we can do without them having housing... meet us halfway. Having more options for housing.” Additionally, P2 had similar thoughts on housing and the systems at large, saying,

I mean these people shouldn't be homeless, so I mean it really bags up, it's a bit beyond our or I believe it's beyond my power of doing anything in the interim I mean it needs to be politically willed or politically changed (P2). 
The barriers affecting both the service providers and the service users are greater than palliative care itself or those with terminal diagnoses who also have insecure housing. These areas of insecurity place a direct burden on the healthcare system. P4 discusses the impact of being vulnerably housed and how that label itself can be seen as a disease, meaning that service users who have a palliative diagnosis and are vulnerably housed are facing additional barriers that have a significant impact on their health. There is then a need placed on the healthcare system and larger systemic structures that has yet to catch up.

We are typically taught that diseases are a biomedical nature right? But $60 \%$ of what makes Canadians sick is social... and social determinants of health, the number one determinate is income, number two is income, number three is income, number four five six seven is array of factors including housing, food security, social networks, education, it's only number nine that's actually access to a doctor and nurse right? And so how can anyone tell me that homelessness is not a disease, it's a disease of the social determinants of health and to add to that the evidence really shows... in my favour you know homeless individuals in a city like Toronto die at an age of like 34 to 47 years old mortality rate are 2.3 to 4 times higher than the average Canadian baseline population and when we look at all-cause mortality homelessness cuts a person's lifespan by $50 \%$. So homelessness is not just a disease of the social determinates of health it's a terminal disease of the social determinants of health it is a palliative diagnosis of the outside and when you throw on another biological disease on board into a person's body is already dealing with that you're destined for a palliative trajectory and that is so sad that that is a society... that that's what happens in our society and until we change our lens and how we think of it you know we are really going to miss the boat (P4). 
If one simply looks at the social determinants of health, those factors are influenced and either supported or ignored on a political level. If referrals continue to rise, needs continue to go unmet, and the impact of these outcomes will only increase. $\mathrm{P} 4$ highlights that this population is particularly vulnerable to the repercussions of a system that is not meeting the needs. There are layers of oppression that those who are homeless and vulnerably housed face on a multitude of levels. Thus, $\mathrm{P} 4$ is highlighting their lived experience of working with this population and the inequalities that the service user is facing, the barriers they are facing to provide care and the rippling effect of those barriers on the wider community.

Service users are constantly facing barriers such as housing, income, access to care, food, and education. These are systematic barriers that could be reduced or eliminated, if supportive strategies were enacted to improve outcomes for palliative service users who are vulnerably housed or for vulnerably housed individuals. P4 discussed these insecurities and their direct impact on the healthcare system as well as the political landscape.

all be it we are seeing the cumulative effects of this ... of the diseases, of the social determinants of health, poverty, and homelessness but hopefully by you know supporting these patient populations and having the opportunities to tell their stories maybe not directly but sometimes directly, sometimes indirectly being upstream make changes to society eradicating poverty, supporting a national housing strategy, better improving a basic guaranteed income, pharma care, policy that we should could really improve the health of all Canadians (P4).

P4 is discussing a shift that is needed in the way we define disease, how we view healthcare, and how money is spent. Having a population who is homeless or vulnerably housed is affecting 
everyone and to add the label of a palliative diagnosis increased barriers and access for all. Without a change of the political landscape, the barrier to care will continue to increase.

Overall the barriers faced by service users who have a palliative diagnosis that are vulnerably housed or homeless is incredibly high compared to those who have adequate and stable housing. The participants examined these barriers but the fundamental underlying message that was behind each person was that there should not be homeless people, especially when others are living in surplus. However, strategies are in place to indirectly impact this population such as raising the minimum wage, looking at a basic guaranteed income, access to affordable childcare, laws and policies around LGBTQ rights, and improvements to child welfare laws. All of these areas are small stepping stones that collaboratively impact vulnerably housed and homeless individuals.

\section{MAID}

A topic that I had hoped to gain some more insight on was MAID and if there were specific strategies for those who are vulnerably housed or homeless. However, with each passing interview, many of the participants did not have an answer as the passing of MAID was just a year ago. None of the participants had a service user who was vulnerably housed or homeless who wished to access or complete the MAID process. P1 spoke of their experiences with MAID saying “I think I've had 5 MAID cases and they've all been in people's very nice homes...like nothing vulnerable about them". Other participants highlighted that it was predominately service users with higher socioeconomic status who are accessing MAID, which was also highlighted in the first round of data. After hearing some participants discuss how MAID has not impacted their practice or service users yet, the question that re-emerged was access. The question that came to my mind was would a service user who is vulnerably housed or homeless have the ability to pass 
the criteria for the MAID process, when they are living in a chaotic and unstable environment. However, this is not a question that can be answered yet; when asked about service users who are vulnerably housed or homeless, some of the participants discussed service users asking about MAID but with no outcomes.

a couple of them that have asked, they just want to know that it's an option should they decide to use it. Umm... but they haven't. They haven't gone through with it, they haven't actually done the first consultation or with the physician about it they just wanted to know. So it hasn't really impacted us right now (P5).

This is notable to discover if service users are asking for MAID because they think it would mean access to increased healthcare or because they actually want to complete the process. P3 discussed how the homecare intervention was often the first point of access to health care or support for a service user. And simply gaining access to care whether it be formal in a setting like a palliative care unit or hospice, the intervention of homecare was often enough as service users may not have received any medical intervention or care up to that point.

Despite service users within this population not moving beyond asking about MAID as an option, participants said that it would follow the same process as any other individual seeking to receive MAID and there are policies and practice in place for MAID within their organizations. This will be an area of research that should be explored as the MAID process will become more normalized as it evolves.

\section{Success in Death}

Lastly the aim of the research is not to romanticize the concept of what it means to be homeless or vulnerably housed, what it looks like to die in hospice/palliative care unit/shelter/or another environment and to think that every day is a success for the workers. These interviews 
gave a voice and recognition of their work. Hearing the workers' stories, I felt inspired and hopeful at times to think their work is having an impact, to think lives are being changed. But I was reminded of P5 and their experience with one service user. P5 was discussing what they initially thought was a success; getting a service user into hospice. However, despite the initial feeling of success the death was still hard for them and the team, saying,

he wouldn't even take pain medication, he wouldn't take and he was in so much pain and I remember telling him please take the pain medication and he said no after everything I've been through 'no one deserves the satisfaction knowing that they have helped me'. And I was like you don't have to fight anymore please. He's been through so much and he's like and 'I don't want you to think that you helped me I haven't been helped'. It was just really hard for me that was a really hard death for me (P5).

This moment sticks out for me as a researcher because this is a voice of the service user; someone who has experienced significant trauma over their life. It appears that he was only supported or shown empathy or care nearing the end of his life. But where were the other interventions prior, how did it come to this point? It highlights larger structural failings of a country; it also highlights the power of this worker, their desire to practice from a client-centred approach, a place of empathy, empowerment, and respect for the autonomy and decisions of the service user despite their own thinking or emotional feelings on the matter. There was no collective discussion of difficult deaths or voice from service users the participants have supported. However, this impacted my analysis and experience as a research and as a future practitioner. As a focus on trauma and service users, voices are needed to guide both research and future policy. 


\section{Conclusion}

Overall the conversations with all five participants centred around the importance of interdisciplinary care teams in supporting service users, the power and prevalence of resistance in their work, how to look at their work with a lens of equity instead of equality; moving away from a one size fits all form of care, and the barriers to care that they face within their role and organizations because of the policies and practices that were enacted on a political level that has been created to support service users. There was a hope to uncover more about the MAID process from this specific service user population, however, because of how new MAID is there is not enough data or experiences to have a clearer understanding. The interviews and discussions highlighted each worker's dedication for their role and their passion for supporting this population. They exemplified how challenging the work is both in the context of the role and the constant push needed for more services and resources. 


\section{Chapter 6: Discussion}

In each theme that was brought forward in the findings there was either a clear or underlying connection to the need for housing, guaranteed income, and access to increased supports. Every participant identified these factors would decrease barriers and improve quality of life; however, achieving this change is beyond their role as worker and beyond the organization's role. Rather this change for increased government funding for housing needs to come from a political level. If this idea were implemented it would remove some financial burden from the healthcare system. For instance, looking at the connection between housing and health, a study looked at rooming house residents and their quality of health, it stated, "rooming house residents have much poorer health status than the general population, even when compared to individuals in the lowest income quintile" (Hwang, Martin, Tolomiczenko \& Hulchanski, 2003). Additionally, within the context of service users who reside in shelters there is a connection to the stress of environmental conditions and the development of new or increased health issues (Davis, 1996). Other studies on the connection between health and shelter discussed how homeless and vulnerably housed individuals prioritize other basic needs like food and shelter before physical health (Martins, 2008). This to me exemplifies what the participants were saying, that if shelters and housing were readily available that individuals could prioritize their health as they can have a sense of security that allows them to see past immediate needs like shelter. The idea of increased access to affordable housing and quality housing appears to be such a simple solution; however, these are ideas or concepts that have been spoken about for years. There is work being done daily to try and increase quality of life like the pilot for basic guaranteed income. Therefore, hopefully there will be positive outcomes that make it clear to 
government and voters that these options would help to create a better functioning health care system for everyone, not just those who require palliative supports.

One of the key themes of the interviews was the creativity practiced within the service providers work which was labeled as resistance. The word resistance is a very popular term within social work education specifically when there is an anti-oppressive focus. There is no clear definition of the term 'resistance' in the context of this landscape however; one definition is "active efforts to oppose, fight, and refuse to cooperate with or submit to ... abusive behaviour and.control" (Profitt, 1996, p 25). Resistance in the traditional sense is referred to as overt resistance this can be seen as a social movement, march or protests. (Hollander \& Einwhohner, 2004). Examples of overt forms of resistance would be actions like Take Back the Night marches or the Black Lives Matters protest at Pride Toronto. These are forms of resistance where the target of the action is clear and the message is explicit. However, in the context of these workers' roles, their acts of resistance cannot be overt as they need to work within a system to help support the client; overt forms of resistance could cost them their jobs and then negatively impact the care the service users are receiving. A term that may be more applicable is the concept of covert resistance, it can be defined "acts that are intentional yet go unnoticed (and, therefore, unpunished) by their targets, although they are recognized as resistance by other, culturally aware observers." (Hollander \& Einwhohner, 2004, p. 545). It is important to understand there is no clear definition of resistance and thus the confusion of participants around the term 'resistance' could be for multiple reasons. What is important to note is that despite no clear use of the word 'resistance' was used by the participants, the academic meaning of resistance specifically in social work is embedded into their work. 
The implications of these findings are limited despite being discussed with experienced and notable individuals in the field. The sample size of the interviews could be seen as a limitation as it does not encompass many voices of those in the field. As well, not all front line staff are represented. Additionally, a limitation is not hearing from the service users directly to understand how the care that is being received is or is not impacting them, and if they notice success with an interdisciplinary team versus a uni-professional team. Their voices and opinions were not heard in this paper because of risk and trauma that could be created from interviews. As this paper has a smaller scope, which is to seek out those with lived experiences, there was no financial or other incentive for them to share their story and thus it could be seen as a very intrusive and oppressive paper. Service users' lived experiences are important, and many of those who participated in this study discussed the importance of their feedback and what they think of the service but as a Master of Social Work student, I do not have the means, access or time to take on this larger project.

Overall, despite the studies limitations this research highlighted the importance and success of interdisciplinary healthcare teams specifically within a large city like Toronto. As this is an emerging and evolving topic, additional research needs to continue to be conducted. Ideally this research can be used to inform or guide those interested in palliative care, palliative medicine, homelessness and vulnerably housed individuals for future research on these intersecting identities.

On a personal level, I chose this topic not because I have lived experience, however, I chose this topic because of the work I've done and the impact it has had on me. My interest in this topic came about in a very organic way; I began to work as a palliative care team assistant right around the same time my mother was diagnosed with a form of ALS called predominantly 
upper motor neuron ALS. As her diagnosis progressed I was able to see the needs she had and the reliance on the health care system. Prior to my mother's diagnosis and my change to a new team I was very unaware of the palliative care, unaware of the impact it had on many individuals and the impact it has on the healthcare system. My role on the palliative care team was predominately administrative; however, I got to know many service users through phone calls and daily meetings. On one occasion, I was allowed to go into the community with the team to meet the service users I had been supporting. I was able to go into people's homes within shelters and rooming houses. I was able to see there was a high demand on workers due to a gap in the services and resources; the service providers were often working beyond their role in community to have service users' needs met and heard. I wanted to focus my major research paper on palliative care and specifically those service users who are vulnerably housed because they are often an afterthought in health care. They often do not have family members calling in everyday to request more services or more equipment; service providers often refuse to provide care depending on the conditions of their homes, and equipment providers are often reluctant to send too much equipment. Thus, going into this journey with some knowledge of a service providers experience I still had significant learning throughout the process. My biggest take-away from the discussions was my shift in perspective. My understanding of what homeless or vulnerably housed means, and the implications of those identities and labels has been enriched. Specifically, hearing participants how they view, treat and practice homelessness as a disease, was a pivotal moment in my learning and understanding of the population. Homelessness is understood as a disease in itself as a result of the implications of the lack of access to basic necessities. This concept highlights the need for the workers' roles to strive to continue to fight for access to basic necessities until the government and policies achieve affordable housing and a guaranteed 
income Finally I realized the implication that a palliative diagnosis for a service user who is homeless or vulnerably housed has on an individual but also the larger structural systems. We are taught social determinants of health through a medical lens but we are also taught to fight for affordable housing and access to housing on a grassroots level. These are two communities that may have different fundamental values at times but their message on homelessness and thus housing is the same. How on a political level, there is not more discussion or acknowledgment that this is a crisis is incredibly troubling. However, the participants continue to work to make this population visible and supported so their efforts are not going unnoticed by those within the field.

One of the questions that inspired this research of this population was the Seaton House revitalization in Toronto. There are mixed feelings and opinions on the revitalization, many may see it as a positive, having a facility or facilities that are newer and continue to support those marginalized individuals. However, there is still no clear answer from the government on whether or not new facilities will provide care for the same number of people as Seaton House provided. Their plans with respect to numbers have not been explicitly explained to the public and how they plan to match the demolished beds. The participants were asked questions about the revitalization during the interviews; some had no idea about the projects plans and others said they were unable to speak to it. This question around the impact of Seaton House revitalization was not unearthed as it is still being developed. Therefore, I like everyone else will continue to wait with bated breath in hopes that a positive decision is made.

One aspect of hope or positivity for the future of palliative care and palliative medicine that came from the interviews was the discovery of a hospice opening in 2019 in Toronto for the vulnerably housed and homeless. The participants were not able to share many details about this 
project but said that the timeline is for spring of 2019. This is a positive sign that their concerns around this population and access to care are heard and hopefully it will support the transition of the impact of the Seaton House revitalization.

This particular study was conducted with five healthcare professionals representing different roles and educational backgrounds. Despite not all participants being part of social work. the findings and research has implications for social work. Aging, housing and access to care have always been part of social work within a worker's role and thus this is an area of study that connects many aspects of social work to one particular population. I think death and dying is something rarely talked about especially in a classroom setting, and there needs to be an understanding that these are issue that will continue to grow and impact large sections of the population. As the large sections of the population age there is a great demand put on healthcare, supportive housing and community supports. This is a field that needs increased interest, attention and supports from social workers and other healthcare professionals alike. Healthcare, death and dying are not issues that only affect the elderly; social work programs with a focus of gerontology would take on this work, but it needs to be expanded beyond the elderly population. This research highlighted that palliative care and homelessness affects every person, despite age, race, gender, religion, and educational background. There needs to be a focus on death and dying in all streams of study in social work and not just directed at those in gerontology.

Palliative care for the homeless and vulnerably housed service users not only has a direct implication to social work but is also relevant to anti-oppressive practice. Even the theme that was brought forward about equity and equality is at the core of anti-oppressive practice. There is a clear understanding that in this particular instance a group of people need more supports which is not them taking away access from others but achieving the bare minimum of care for 
themselves. The way the workers practice their role, incorporating resistance/creativity into their practice to ensure service users have access to supports and supplies, exemplifies working from an anti-oppressive practice stance. Anti-oppressive practice is embedded into each of the participant's practice; however, this is not part of their job requirement or something that is outlined in their role. It is an individual choice about how they choose to practice. I wonder if there could be a connection to the population they support and why they chose to practice this way or if it is because of previous teachings or experiences that they enter this work. Overall, palliative care specifically for the homeless and vulnerably housed is directly tied to antioppressive social work practice and without this incorporation of critical thinking then service users will only receive minimum support. 


\section{Chapter 7: Conclusion}

The discussion around palliative care and particularly palliative care for service users who are homeless or vulnerably housed can seem to appear particularly grim. However, speaking to this interdisciplinary care team who are working at community level has shed light on the work being done to create a richer and more informed field of professionals as well as resources. This team works in collaboration with each other and other organizations/agencies to ensure the service users are supported and heard. Their interviews were captivating; the concepts of palliative care, health, death, and dying are often not topics discussed in social work or in a wider context. The results of the research shed light on what their work looks like, how power structures influence each decision and how they use the system as tool to achieve the service users' goals. Their interviews gave a voice to their experiences as a worker and how they are working from a grassroots level to provide care, see change within healthcare and provide effective palliative care.

The landscape of healthcare will continue to evolve or devolve depending on the political party and their willingness to acknowledge a need for this population and palliative care/ palliative medicine. Death and dying impacts everyone, however, receiving palliative care or having the label of homelessness or vulnerably housed may not be true for everyone. Consequently, each of these identities affect the healthcare system and thus impacts the wider

population. Without a collective understanding of how we are all impacted by these identifies, a willingness to see positive changes and more accessible supports for all then collectively the healthcare system will continue to struggle to meet needs. 
RYERSON

UNIVERSITY

\section{PARTICIPANTS NEEDED FOR RESEARCH IN PALLIATIVE CARE FOR THE HOMELESS AND VULNERABLY HOUSED}

Are You:

A health care professional who provides support to service users with a palliative diagnosis who are homeless or vulnerably housed?

- Including care coordinators, nurse practitioners, community nurses, physicians, etc.

If you answered yes to the above noted questions, you are invited to volunteer in this study of

“Allowing Service Users To Die At Home: Palliative Care For Vulnerably Housed And Homeless Individuals"

You will be asked to participate in a one on one interview to discuss your role. Looking at how you're providing care to meet the needs of service users who are homeless or vulnerably housed with a palliative diagnosis. Also looking at how health care professionals are working collaboratively to support this population.

Please note that participation involves taking part in an interview that will take up to 1.5 hours.

If you are interested in participating in this study or for more information, please contact:

Taggart Archer at taggart.archer@ ryerson.ca

This research study has been reviewed and approved by the Ryerson University Research Ethics Board and the JREB. 


\section{References}

Baines, S., \& Edwards, J. (2015). Considering the ways in which anti-oppressive practice principles can inform health research. The Arts in Psychotherapy, 42, 28-34. doi:10.1016/j.aip.2015.01.001

Belsey, C. (2002). Poststructuralism: A very short introduction. New York, NY: Oxford University Press.

Brinkmann. S., \& Kyale, S. (2015). InterViews: Learning the craft of qualitative research interviewing (3rd ed.). Los Angeles, CA: Sage Publications.

Canadian Observatory on Homelessness (2012). Canadian definition of homelessness. Ottawa, ON: Homeless Hub. Retrieved from: www.homelesshub.ca/homelessdefinition/

City of Toronto. (n.d.). Reinventing life on George Street. Retrieved from https://www1.toronto.ca/wps/portal/contentonly?vgnextoid=a5dfd9f9849b2410VgnVCM 10000071d60f89RCRD

Davis, R. E. (1996). Tapping into the culture of homelessness. Journal of Professional Nursing, 12(3), 176-183. doi:10.1016/S8755-7223(96)80042-1

Foucault, M. (2011). Questions of method. In G. Burchell, C. Gordon, \& P. Miller (Eds.), The Foucault effect: Studies in governmentality with two lectures by and an interview with Michel Foucault. (pp. 73-86) Chicago, IL: The University of Chicago Press.

Gallagher, S. (2012). Phenomenology. New York, NY: Palgrave.

Harris, P. (2001). Towards a critical post-structuralism. Social Work Education, 20(3), 335-350. doi: 10.1080/02615470120057424

Hollander, J. A., \& Einwhohner, R.L. (2004) Conceptualizing resistance. Sociological Forum, 19(4), 533-554. doi:10.1007/s11206-0040694-5 
Hwang, S. W., Martin, R. E., Tolomiczenko, G. S., \& Hulchanski, J. D. (2003). The relationship between housing conditions and health status of rooming house residents in Toronto. Canadian Journal of Public Health / Revue Canadienne De Santé Publique, 94(6), 436440.

Kawash, S. (1998). The homeless body. Public Culture: Bulletin of the Project for Transnational Cultural Studies, 10(2), 319-339.

Ko, E., Kwak, J., \& Nelson-Becker, H. (2015). What constitutes a good and bad death? Perspectives of homeless older adults. Death Studies, 39(7), 422-432. https://doi.org/10.1080/07481187.2014.958629

Ko, E., \& Nelson-Becker, H. (2014). Does end-of-life decision making matter? Perspectives of older homeless adults. American Journal of Hospice and Palliative Medicine, 31(2), 183188. doi: $10.1177 / 1049909113482176$

Körner, M. (2010). Interprofessional teamwork in medical rehabilitation: A comparison of multidisciplinary and interdisciplinary team approach. Clinical Rehabilitation, 24(8), 745755. doi:10.1177/0269215510367538

Krakowsky, Y., Gofine, M., Brown, P., Danziger, J., \& Knowles, H. (2013). Increasing access-A qualitative study of homelessness and palliative care in a major urban center. The American Journal of Hospice \& Palliative Care, 30(3), 268-70. doi:

\section{$10.1177 / 1049909112448925$}

Leung, A. K., Nayyar, D., Sachdeva, M., Song, J., \& Hwang, S. W. (2015). Chronically homeless persons' participation in an advance directive intervention: A cohort study. Palliative Medicine, 29(8), 746-55. https://doi.org/10.1177/0269216315575679 
Lopez, K. A., \& Willis, D. G. (2004). Descriptive versus interpretive phenomenology: Their contributions to nursing knowledge. Qualitative Health Research,14(5), 726-735. doi:10.1177/1049732304263638

Martins, D. C. (2008). Experiences of homeless people in the healthcare delivery system: A descriptive phenomenological study: Populations at risk across the lifespan: Empirical studies. Public Health Nursing, 25(5), 420-430. https://doi.org/10.1111/j.15251446.2008.00726.x

McCracken. G, D. (1988). The long interview. Newbury Park, CA: SAGE

McNeil, R., \& Guirguis-Younger, M. (2012). Illicit drug use as a challenge to the delivery of end-of-life care services to homeless persons: Perceptions of health and social services professionals. Palliative Medicine, 26(4), 350-359. doi: 10.1177/0269216311402713

Mcneil, R., Guirguis-Younger, M., \& Dilley, L. B. (2012a). Recommendations for improving the end-of-life care system for homeless populations: A qualitative study of the views of Canadian health and social services professionals. BMC Pallaitiave Care, 11(1) 14. doi: $10.1186 / 1472-684 X-11-14$

McNeil, R., Guirguis-Younger, M., Dilley, L. B., Aubry, T. D., Turnbull, J., \& Hwang, S. W. (2012b). Harm reduction services as a point-of-entry to and source of end-of-life care and support for homeless and marginally housed persons who use alcohol and/or illicit drugs: A qualitative analysis. BMC Public Health, 12(1), 312 doi: 10.1186/1471-2458-12-312

Nancarrow, S. A., Booth, A., Ariss, S., Smith, T., Enderby, P., \& Roots, A. (2013). Ten principles of good interdisciplinary team work. Human Resources for Health, 11(1), 19. doi:10.1186/1478-4491-11-19 
OCAP. (2015, August 11). Sign on to this statement! Demand the city of Toronto enforce its own shelter standards and prevent the ongoing gentrification of the downtown! Retrieved from https://www.facebook.com/OcapToronto/posts/1194901363869561

Partis, M. (2003). Hope in homeless people: A phenomenological study. Primary Healthcare Research and Development,4(1), 9-19. doi:10.1191/1463423603pc118oa

Podymow, T., Turnbull, J., \& Coyle, D. (2006). Shelter-based palliative care for the homeless terminally ill. Palliative Medicine, 20(2), 81-86. doi: 10.1191/0269216306pm1103oa

Podymow, T., Turnbull, J., Coyle, D., Yetisir, E., \& Wells, G. (2006). Shelter-based managed alcohol administration to chronically homeless. Canadian Medical Association, 174(1), 4549.

Profti, N. J (1996). Battered women' as 'victims' and 'survivors': Creating space for resistance. Canadian Social Work Review/Revue Canadienne de Service Social, 13(1), 23-38.

Shapcott, M. (2013). Toronto's homeless population continues to grow: Latest city count. Retrieved from http://www.wellesleyinstitute.com/housing/torontos-homeless-populationcontinues-to-grow-latest-city-count/

Smith, J., \& Osborn, M. (2015). Interpretative phenomenological analysis. In J. Smith (Ed.), Qualitative psychology: A practical guide to research methods (3rd ed., pp. 54-80). London, UK: SAGE.

Sokolowski, R. (2008). Introduction to phenomenology. Cambridge, UK: Cambridge University Press.

Song, J., Bartels, D. M., Ratner, E. R., Alderton, L., Hudson, B., \& Ahluwalia, J. S. (2007a). Dying on the streets: Homeless persons' concerns and desires about end of life care. Journal of General Internal Medicine, 22(4), 435-441. doi: 10.1007/s11606-006-0046-7 
Song, J., Ratner, E. R., Bartels, D. M., Alderton, L., Hudson, B., \& Ahluwalia, J. S. (2007b).

Experiences with and attitudes toward death and dying among homeless persons. Journal of General Internal Medicine, 22(4), 427-434. doi: 10.1007/s11606-006-0045-8

Song, J., Ratner, E. R., \& Wall, M. M. (2010). An end-of-life planning intervention in homeless adults. Journal of Clinical Outcomes Management, 17(11), 12-15.

Song, J., Wall, M. M., Ratner, E. R., Bartels, D. M., Ulvestad, N., \& Gelberg, L. (2008).

Engaging homeless persons in end of life preparations. Journal of General Internal Medicine, 23(12), 2031-2045. doi: 10.1007/s11606-008-0771-1

Starks, H., \& Trinidad, S. B. (2007). Choose your method: A comparison of phenomenology, discourse analysis, and grounded theory. Qualitative Health Research,17(10), 1372-1380. doi:10.1177/1049732307307031

Sumalinog, R., Harrington, K., Dosani, N., \& Hwang, S. W. (2016). Advance care planning, palliative care, and end-of-life care interventions for homeless people: A systematic review. Palliative Medicine, 31(2), 109-119. doi: 10.1177/0269216316649334

Verschueren, S., Berends, T., Kool-Goudzwaard, N., Huigenbosch, E., Gamel, C., Dingemans, A., ... Meijel, B. (2015). Patients with anorexia nervosa who self-injure: A phenomenological study. Perspectives in Psychiatric Care, 51(1), 63-70. doi: $10.1111 /$ ppc. 12061

Williams, J. (2005). Understanding poststructuralism. Abungdon, Oxon, UK: Rutledge. 